\title{
Anorexia nervosa with purgative \\ behaviour: abuse or dependence of diuretics? A case report
}

\section{Peixoto1, J. Coelho', H. Medeiros ${ }^{1}$, D. Rego'}

${ }^{1}$ Hospital do Divino Espírito Santo de Ponta Delgada, Psychiatry, Ponta Delgada, Portugal

\section{Background/ Objectives}

Anorexia nervosa (AN) is a disorder characterized by deliberate severe weight loss, induced and sustained by the patient, and secondary problems due to malnutrition. The symptoms include reduction in food intake, excessive exercise and purgation. A common mean of purging is through diuretic and laxatives abuse. ${ }^{1}$

The aim of the authors is to describe and discuss a clinical case of a patient with $\mathrm{AN}$ with a long term abuse of furosemide.

\section{Materials and Methods}

Case report and a non-systematic review through research in Pubmed/Medline database.

\section{Results}

\section{Case report}

\section{0 year-old woman, divorced, unemployed}

$>$ At 18 starts restricting food intake

Distorted body image with purgative behaviour and use and fear of becoming of diuretics (furosemide) in order to lose weight

overweight

First hospital admission at the age

of 25 with a body mass index (BMI) of $12,81 \mathrm{~kg} / \mathrm{m}^{2}$, hypokalaemia and acute kidney injury

Treated with a combination of fluoxetine and olanzapine

\section{Multiple emergency department} admissions (lipothymia, dizziness, oedema)

\section{Sustained harmful use of furosemide}

\section{September 2018}

\section{Restricted food intake and severe purgative}

behaviour - abuse of furosemide and self-induced vomiting

\section{Admitted on Emergency department}

- BMI 13,68 kg/m²,

- Acute kidney lesion,

- Severe hypokalaemia (1,9 mmol/L)

- Oedema

\section{Abuse of furosemide}

- 40 to 60 pills of furosemide $40 \mathrm{mg}$ per day

- progressively used higher dosage to achieve diuretic effect

- difficulty in the control of its use, despite the harmful consequences

- spent all of her income and lot of her time getting strategies to buy it

$>$ During hospitalization the dose of furosemide was gradually reduced with improvement of electrolyte disturbance and oedema

$>$ Fluoxetine was titrated to a dose of $60 \mathrm{mg}$ per day and olanzapine to $20 \mathrm{mg}$ per day

- Clinical evolution with gradual improvement of purgative behaviours until their non-presentation

- Discharged after 77 days of hospitalization with BMI of $18,51 \mathrm{~kg} / \mathrm{m}^{2}$

\section{Case discussion}

According to ICD-10, diuretic abuse is classified as F55 Abuse of non-dependence-producing substances. However, although diuretics aren't a psychoactive substance, according to the ICD-10 dependence criteria, in this case there are also characteristics of a dependence syndrome, such as the dose increase over many years with tolerance development, the strong desire to take the drug and difficulty in controlling its use, persisting in its use despite harmful consequences and higher priority given to use it than to other activities and obligations. $^{1}$

There are other cases of diuretic abuse described in literature. ${ }^{2-6}$ This abuse is described both in cases of $\mathrm{AN}^{2,3,4}$ and Bulimia Nervosa ${ }^{5,6}$. The most commonly abused diuretic is furosemide. ${ }^{6}$

\section{Conclusion}

This case demonstrates a severe case of $\mathrm{AN}$ with restrictive and purgative behaviours with a co-morbid diuretic abuse, possibly with enough criteria to diagnose substance dependence. 